\title{
Mortality from Diabetes by Hispanic Groups: Evidence from the US National Longitudinal Mortality Study
}

\author{
Augustine J. Kposowa \\ Department of Sociology, University of California, 1150 Watkins Hall, Riverside, CA 92521, USA \\ Correspondence should be addressed to Augustine J. Kposowa; augustine.kposowa@ucr.edu
}

Received 26 June 2013; Revised 2 September 2013; Accepted 12 September 2013

Academic Editor: Alberto Davila

Copyright (C) 2013 Augustine J. Kposowa. This is an open access article distributed under the Creative Commons Attribution License, which permits unrestricted use, distribution, and reproduction in any medium, provided the original work is properly cited.

Diabetes is a leading cause of morbidity and mortality in the United States, especially in minority communities. In mortality research, Hispanics are frequently studied as a homogeneous group. The present study was undertaken to compare diabetes deaths among persons of Hispanic origin by disaggregating groups in order to determine whether the components in the Hispanic label have differential mortality. Data utilized were from the US National Longitudinal Mortality Study. Cox proportional hazards regression models were fitted to the data. Findings showed that individuals in the broader Hispanic label were $28 \%$ more likely to die from diabetes mellitus than non-Hispanic whites ( $\mathrm{ARR}=1.28, \mathrm{CI}=1.05,1.55)$. When groups were broken down, it was observed that Mexicans were $50 \%$ more likely to die of diabetes than their non-Hispanic white counterparts. No other Hispanic origin group was significantly associated with diabetes mortality risk. Education and family income were strong predictors of mortality, regardless of Hispanic origin grouping. It was concluded from the analysis that future behavioral and social science research would be more informative if the broader Hispanic label was broken down into subcategories. Failure to do so might lead to drawing false inferences as a finding may well hold for one group within the Hispanic label, but not for others.

\section{Introduction}

Diabetes is a heterogeneous group of metabolic disorders marked by hyperglycemia (high serum glucose) due to insulin resistance or diminished capacity by the pancreas to produce insulin [1-3]. The most common of these metabolic disorders is type 2 diabetes (formerly called noninsulin dependent diabetes mellitus) which accounts for $90 \%$ to $95 \%$ of all persons diagnosed with diabetes [4].

Recent data show that in 2007, among all age groups in the United States, 23.6 million persons (7.8\% of the population) had diabetes [5]. Of this number, 17.9 million comprised individuals diagnosed with the disease; the undiagnosed consisted of 5.7 million [5]. Diabetes prevalence rates among persons older than 20 years show that in 2005 , while $6.6 \%$ of non-Hispanic whites had diabetes, visible minority group members had much higher rates. They were $7.6 \%$ for Asian Americans, 10.4\% for Hispanics, and 11.8\% for non-Hispanic African Americans. Among Hispanics prevalence rates were
8.2\% for Cubans, $11.9 \%$ for Mexican Americans, and $12.2 \%$ for Puerto Ricans [5].

Studying risk factors for diabetes remains a public health priority as the disease now ranks as the 7th leading cause of death in the US [6, 7, page 9]. From 1988 to 1994 and 2005 to 2006, diabetes prevalence went from $9.6 \%$ to $12.6 \%$ in the adult Hispanic US population [8-10, page 336]. Diabetes has been implicated by some studies in the incidence of other serious chronic health conditions, including heart disease and stroke [11], end-stage renal disease [12], diabetic retinopathy and, nontraumatic limb amputations [5]. Direct medical costs to the US economy have been estimated at $\$ 116$ billion, and indirect costs (due to disability, work loss, and premature deaths) have been put at $\$ 58$ billion [5]. Worldwide, incidents of diabetes are reported to be on the increase [13].

Despite a substantial increase in the number of studies on diabetes onset, our understanding of the contribution of social factors to mortality from the disease remains 
limited. Furthermore, when studying racial/ethnic disparities in mortality, comparison is often limited to non-Hispanic whites, non-Hispanic African Americans, and Hispanics as a homogeneous group. Data limitations often preclude disaggregating Hispanics by subgroups of the Hispanic origin population. It thus remains unclear whether the contribution of social factors to mortality varies by Hispanic origin subgroups.

The purpose of this research was to capitalize on newly available data to investigate risk factors for diabetes mortality among Hispanics. With Hispanics projected to replace nonHispanic whites as the dominant group in the United States by 2050 , it is important to concentrate on understanding their health and mortality patterns. The specific questions to be addressed are the following: (1) are there significant disparities in diabetes mortality among specified Hispanic subgroups? (2) if so, are the disparities reduced or eliminated once we control for socioeconomic position, primarily education, and income?

\section{Past Research}

In 1950, the age-adjusted death rate for diabetes was 23.1 per 100,000 population. The rate increased to 24.3 in 1951, but by 1982 , it had declined to 17.2 . Mortality rates for all racial/ethnic groups then increased remarkably between 1985 and 2000 [14]. As may be seen in Figure 1, since 2003, mortality rates have been on a decline. Despite the mortality declines, substantial disparities remain between racial/ethnic groups, with rates being much higher among non-Hispanic African Americans, American Indians/Native Alaskans, and Hispanics or Latinos. From 1985 to 2010, the only minority group with lower mortality rates than non-Hispanic whites was Asian or Pacific Islanders. In other words, diabetes death rates in that period were higher for all visible minorities compared to non-Hispanic whites. It is also important to note that despite the declines, diabetes mortality rates are still higher than they were in 1985, and this is true for all racial/ethnic groups (see Figure 1).

The US Centers for Disease Control [15] conducted a study which concluded that Hispanic Americans are at particularly high risk for developing type 2 diabetes, which has been shown to be associated with family history of diabetes, older age, obesity, and race/ethnicity. Diabetes is currently the fifth leading cause of death among persons of Hispanic origin (combined). The CDC [15] study noted that, between 1998 and 2002, diabetes more than doubled for Hispanics who were obese. For instance, among Hispanics with a body mass index (BMI) less than or equal to 25 , 7 percent reported having diabetes, but the corresponding percent for those with BMI greater than or equal to 30 was 15.3 [15].

Using the 2000-2005 National Health Interview Survey, Pabon-Nau et al. [16, page 849] assessed demographic and disease related differences among US Hispanics by country of origin. After disaggregating Hispanics, they found significant differences in diabetes prevalence by subgroup. They reported that overall prevalence of the disease ranged from

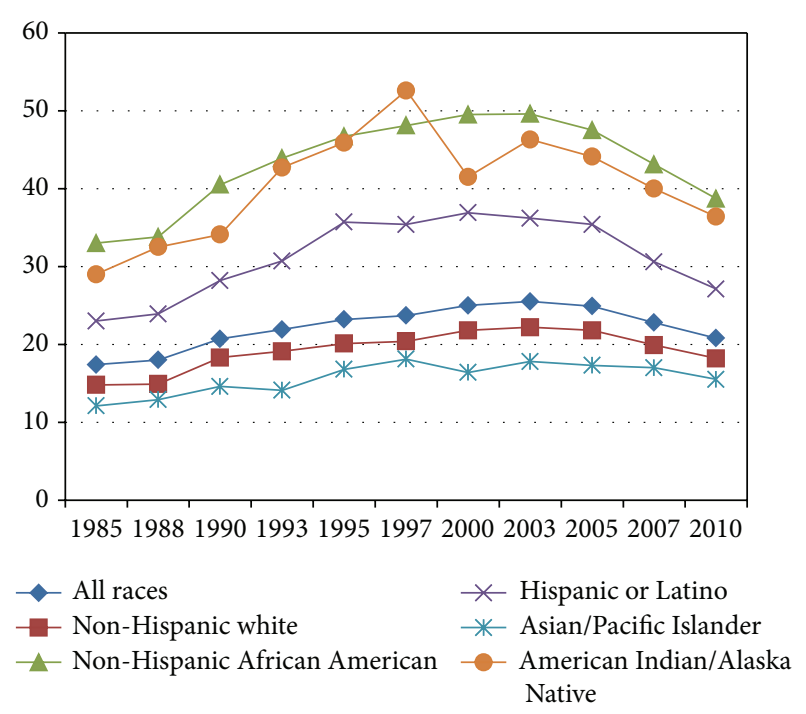

FIGURE 1: Diabetes mortality by race/ethnicity, selected years, 19852010, USA. Source: National Center for Health Statistics [14].

$4 \%$ for Central/South Americans to $11 \%$ for Puerto Ricans. Among US born Hispanics, diabetes prevalence was lower for Mexicans $(\mathrm{OR}=0.76)$. They observed that, for foreign born Hispanic groups, diabetes prevalence remained significantly lower in adjusted equations for Cubans $(\mathrm{OR}=0.42)$, Dominicans $(\mathrm{OR}=0.49)$, and Central/South Americans $(\mathrm{OR}=0.51)$. The reference group in the study was foreign born Mexican Americans. Pabon-Nau et al. [16] speculated that differences in diabetes prevalence among foreign born Hispanics might be due to interaction with the health care system of the country of origin, exercise and dietary differences, and family stressors that may impact individuals differently based on country of origin.

Although the Pabon-Nau study was innovative in breaking down Hispanics by subgroups, the focus was on diabetes and hypertension prevalence based on self-reports (instead of diagnostic records). The data used were also cross-sectional, and they failed to place the various Hispanic groups within the context of the larger US racial mosaic.

Some studies have observed what has been termed a "Hispanic paradox" in mortality [17-21]. The paradox is typified by lower all-cause mortality rate for Hispanics compared to their non-Hispanic counterparts. It is unclear, however, whether the paradox holds for cause-specific mortality. It has been reported in one study [22] that although Hispanics exhibit lower overall mortality compared to whites, there are differentials within the broader Hispanic label. Other studies caution against the use of a "Hispanic paradox," noting that there are significant differences in health profiles between Hispanics born in the United States and those born abroad [21, 23]. The entire line of research on the Hispanic paradox has come under heavy criticism from many analysts on grounds that it engages in drawing conclusions that overgeneralize about different groups that come from divergent socioeconomic and ethnic backgrounds [21] and data quality problems [24]. Salinas et al. [21], for example, 


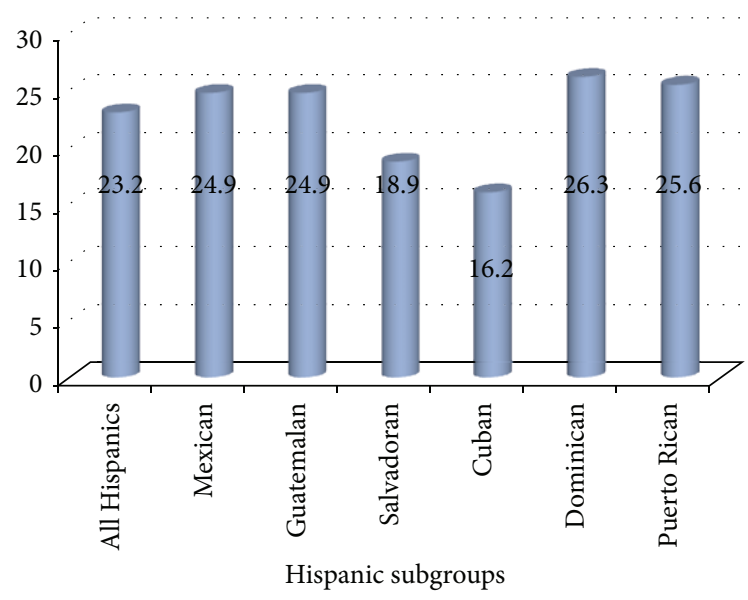

FIGURE 2: US poverty rates for selected Hispanic groups, 2007-2011. Source: US Census Bureau [27]. Note that rate represents percent in poverty.

observed that even within a given group, there may be cultural diversity, noting that the Mexican-origin Hispanic population is diverse in terms of both ethnicity and socioeconomic status.

Data from national epidemiologic surveys show that Mexican Americans are almost twice as likely as nonHispanic whites to be diagnosed with diabetes by a physician [25]. Mexican Americans also have higher rates of end-stage renal disease, caused by diabetes, and they are $50 \%$ more likely to die from diabetes than non-Hispanic whites [25].

Poverty has been cited by some analysts as a risk factor for diabetes and one that might potentially explain disparities in prevalence among Hispanic origin groups [13, 21, 23]. Poverty is tied to many other causes of death in the United States, including sexually transmitted diseases and HIV, cerebrovascular diseases, and various neoplasms $[19,26]$. There are significant variations in US poverty rates by Hispanic origin. As seen in Figure 2, for all Hispanics, the poverty rate in 2007-2011 (annual average) was $23.2 \%$. When Hispanics are broken down by selected groups, Dominicans had the highest rate (26.3\%), followed by Puerto Ricans (25.6\%), and Mexicans and Guatemalans with $24.9 \%$, respectively. The lowest poverty rate (16.2\%) was observed among Cuban Americans.

The evidence from the aforementioned and many other studies suggests the need to disaggregate Hispanic origin subgroups in mortality research. As has been pointed out by some analysts $[11,28]$, Hispanics in the United States are a heterogeneous group, and, apart from sharing a common language (Spanish), they are culturally and ethnically diverse [29]. Failure to account for this might mask potentially important sources of variation in disease or mortality risk and lead to the drawing of inferences that might hold for one subgroup but not for others. In the present study, it is hypothesized that there are differentials in diabetes mortality among Hispanic groups. It is further hypothesized that socioeconomic status explains the mortality disparities.

\section{Methods}

3.1. Data. Data were derived from the latest release of The US National Longitudinal Mortality Study (NLMS). The NLMS is a prospective study of mortality among the noninstitutionalized population in the United States, and it was conducted by the National Heart, Lung, and Blood Institute in collaboration with the National Center for Health Statistics and the US Bureau of the Census [30, 31]. The samples were derived from the Current Population Surveys (CPS), which are conducted by the US Bureau of the Census [32].

In the Current Population Surveys, a probability sample of households is surveyed monthly through personal and telephone interviews to obtain information on social, economic, and demographic characteristics about the US population [32]. The public use data file employed in the present study consisted of a cohort of 11 national samples derived from the Current Population Surveys conducted in 1980, 1981, 1982 and 1983. Weights on the records were adjusted to reflect the noninstitutionalized population distribution of the United States as of 1 April 1983. It was assumed that the 11 surveys, which were collected in 1980,1981, 1982, and 1983, reflect the US non-institutionalized population as of April 1, 1983. Thus, the 11 samples were combined and considered as one large sample taken on April 1, 1983. Original weights were reweighted to reflect the size of the US population at that time. The samples were then designated as "cohorts" for mortality followup and survival analysis. The individuals were known to be alive on the survey date and, therefore, eligible for followup with regard to survivorship from April 1983. The mortality experiences of sample members were studied until 1994. Data from death certificates on the fact and cause of death were combined with the socioeconomic and demographic characteristics of the 1983 population cohorts using the National Death Index (NDI) to link the two databases. A more detailed description of the data collection process, including sample selection, has been presented elsewhere $[30,31,33]$.

3.2. Variables and Measures. The dependent variable was the risk of mortality from diabetes mellitus (250). Cause of death was identified using the International Classification of Diseases, 9th Revision, Clinical Modification [34]. In estimating the risk of mortality from diabetes, all persons surviving beyond the 11-year followup along with persons dying of other causes were treated as right censored observations. The sample comprised 579, 566 individuals 25 years old and above at the beginning of the study, of whom 1874 had died from diabetes by the end of the eleven-year followup period. This means that, of the 87,242 deaths that took place from all causes in the age group considered during followup, $2.1 \%$ were from diabetes. The present analysis was restricted to mortality among non-Hispanic whites, Hispanics as a group, and various Hispanic subgroups: Cubans, Mexican Americans, Puerto Ricans, Central and South Americans, and all other (unspecified) Hispanics. Data analysis was also limited to persons 25 years or above because, although type 2 diabetes is increasing rapidly among children and young 
adults, it is still more prevalent among persons aged 25 and above $[12,22,35,36]$. It is known that 90-95 percent of cases diagnosed with diabetes fall in the category of type 2 , and it is more likely to afflict people over 25 years [4].

Race/Ethnicity was initially defined in terms of 3 dummy variables, one for non-Hispanic African Americans, one for Hispanics, and one for non-Hispanic other races (including Asian and Pacific Islanders/Native Hawaiians, Native Americans, and Alaskan natives). Non-Hispanic whites constituted the reference group. In further analysis, Hispanic origin groups were disaggregated, and there were 1 for Mexican Americans, 1 for Cuban Americans, 1 for Puerto Ricans, and 1 for other Hispanic groups that had too few observations to be included as separate covariate categories. In the whole analysis, non-Hispanic whites were the reference group.

Education was measured by two dummy variables, one for less than high school education and one for high school education (12 years completed). Individuals with 13 or more years of education constituted the reference group.

Health Insurance Availability was measured as a dummy variable. Persons that had no health insurance of any kind (public or private) were coded 1, and the reference group comprised individuals with health insurance.

Income was indexed by annual family income (adjusted for inflation), It was indexed by 6 dummy variables, one each for less than $\$ 10,000, \$ 10,000-\$ 19,999, \$ 20,000-29,999$, and one for $\$ 30,000-\$ 39,999$. Those with family income of $\$ 40,000$ or more were the omitted group.

Marital Status was measured by a dummy variable, one for those not married, and persons married at the beginning of the study constituted the reference category.

Nativity Status was measured by a dummy variable, with 1 for persons born outside the United States and US born persons constituting the reference category.

Central City Residence was measured as a dummy variable. Individuals living in central cities of urbanized areas (MSAs) were coded 1 , and those living outside the central city (e.g., suburbs) were the reference category.

Age at the baseline was captured by defining it in terms of two dummy variables, one each for age groups 45-64 and 65 or above. The age group 25-44 served as the reference category.

Sex was measured as a dummy variable with males coded 1 ; women were the reference group for comparison.

3.3. Statistical Methods. Cox's [37] proportional hazards model was applied to the NLMS data to compare the risk of diabetes among racial/ethnic groups while controlling for confounders. The Cox model may be specified as

$$
h(t)=h_{0}(t) \exp \left(\Sigma_{k} \beta_{k} X_{k}\right),
$$

where $h(t)$ is the hazard or risk of mortality at time $t, \beta_{k}$ 's are a set of unknown parameters to be estimated, and $X_{k}$ 's are $k$ covariates. $h_{0}(t)$ is a baseline hazard function and is defined when all the covariates in the model are set to zero. Parameters were estimated by the method of partial maximum likelihood using the PHREG procedure available within SAS, version 9.3 [38].

\section{Result}

The results are divided into three sections. In the first one, bivariate associations are presented, where covariates are adjusted for only age. In the second stage, Hispanics are combined and presented as one racial/ethnic group. The third section disaggregates the Hispanic groups in an effort to determine whether there are mortality differentials among the various groups.

Table 1 presents event counts, population at risk, and gross (unadjusted) effects of the covariates on mortality from diabetes during the eleven-year followup. As may be observed in Table 1, race/ethnicity is a risk factor for death from diabetes. However, among Hispanic subgroups, significant results were found for only Mexican Americans. Mexican Americans were 2 times more likely to die of diabetes than their non-Hispanic white counterparts. Non-Hispanic Blacks were a little over 2 times as likely to die as non-Hispanic whites.

Persons born outside the United States were 23\% ([RR 1] $\times 100$ ) less likely to die of diabetes than those born in the United States. Men were 12\% more likely to die than women, and those not married were $55 \%$ more likely to die of diabetes than their married counterparts. Living in the inner city was associated with significantly elevated risk of death. Those living in the central city of metropolitan areas were nearly 1.3 times as likely to die of diabetes as those living outside the central city. There was no significant mortality difference between persons with health insurance and those without. Having less than high school education was associated with significantly higher risk of death. Likewise, having only high school education increased the risk of dying from diabetes. Income inequality as measured by family income was a strong determinant of mortality. For example, individuals in families with less than $\$ 10,000$ per year were 2.9 times as likely to die of diabetes as their counterparts with family income $\$ 40,000$ or above. Increasing age was associated with much higher risk of death.

The remainder of the analysis presents multivariate hazards regression estimates of the effect of Hispanic race/ethnicity, adjusted for socioeconomic and other covariates. First, Hispanics are grouped, and their diabetes mortality risk is compared to non-Hispanic whites. Relevant results are shown in Table 2.

As seen in Table 2, Hispanics as a group were nearly 1.3 times as likely to die from diabetes as their non-Hispanic white counterparts $(\mathrm{ARR}=1.28, \mathrm{CI}=1.05,1.55)$. NonHispanic African Americans had diabetes mortality risk that was 1.5 times more elevated than that of non-Hispanic whites $(\mathrm{ARR}=1.52, \mathrm{CI}=1.32,1.74)$.

Results also show that persons born outside the United States were $32 \%$ less likely to die of diabetes than those born in the United States. Males were $27 \%$ as likely to die of diabetes as females, and nonmarried individuals were $27 \%$ more likely to die than the married. Living in the central city of metropolitan areas increased mortality risk, but health insurance coverage was not associated with diabetes death.

When socioeconomic variables were considered, education and income had significant effects on mortality from 
TABLE 1: Events, population at risk, and gross (unadjusted) hazards regression estimates of the effects of the covariates on diabetes mortality, 1983-1994.

\begin{tabular}{|c|c|c|c|c|c|}
\hline Variable & Diabetes deaths & Population at risk & Hazards regression coefficient & Relative risk & 95\% confidence interval \\
\hline \multicolumn{6}{|l|}{ Race/ethnicity } \\
\hline Non-Hispanic white & 1421 & 478346 & & 1.00 & Reference \\
\hline Mexican & 80 & 20265 & $0.694^{* *}$ & 2.00 & $1.60,2.51$ \\
\hline Puerto Rican & 12 & 4363 & 0.381 & 1.46 & $0.82,2.58$ \\
\hline Cuban & 10 & 2621 & 0.098 & 1.10 & $0.59,2.05$ \\
\hline Other Hispanics & 59 & 22259 & 0.105 & 1.11 & $0.86,1.44$ \\
\hline Non-Hispanic black & 280 & 49299 & $0.758^{* *}$ & 2.13 & $1.87,2.42$ \\
\hline Non-Hispanic other & 47 & 15992 & 0.260 & 1.30 & $0.97,1.73$ \\
\hline \multicolumn{6}{|l|}{ Nativity status } \\
\hline Born in USA & 1813 & 559517 & & 1.00 & Reference \\
\hline Born outside USA & 61 & 21518 & $-0.258^{*}$ & 0.77 & $0.59,0.99$ \\
\hline \multicolumn{6}{|l|}{ Sex } \\
\hline Female & 1055 & 309523 & & 1.00 & Reference \\
\hline Male & 819 & 270043 & $0.111^{* *}$ & 1.12 & $1.02,1.22$ \\
\hline \multicolumn{6}{|l|}{ Marital status } \\
\hline Married & 1045 & 412040 & & 1.00 & Reference \\
\hline Not married & 829 & 166481 & $0.467^{* *}$ & 1.55 & $1.41,1.70$ \\
\hline \multicolumn{6}{|l|}{ Central city residence } \\
\hline Lives outside city & 1274 & 424934 & & 1.00 & Reference \\
\hline Lives in city & 600 & 154632 & $0.234^{* *}$ & 1.26 & $1.15,1.39$ \\
\hline \multicolumn{6}{|l|}{ Health insurance } \\
\hline Has insurance & 860 & 246072 & & 1.00 & Reference \\
\hline Lacks insurance & 1014 & 333494 & 0.026 & 1.03 & $0.94,1.12$ \\
\hline \multicolumn{6}{|l|}{ Educational attainment } \\
\hline Some college & 297 & 198839 & & 1.00 & Reference \\
\hline High school & 468 & 219513 & $0.165^{* *}$ & 1.18 & $1.02,1.36$ \\
\hline Less high school & 1109 & 161214 & $0.823^{* *}$ & 2.28 & $1.99,2.59$ \\
\hline \multicolumn{6}{|l|}{ Family income } \\
\hline Above $\$ 40,000$ & 255 & 185130 & & 1.00 & Reference \\
\hline Less than $\$ 10,000$ & 597 & 90095 & $1.077^{* *}$ & 2.94 & $2.51,3.43$ \\
\hline$\$ 10,000-\$ 19,999$ & 519 & 100664 & $0.858^{* *}$ & 2.36 & $2.02,2.75$ \\
\hline$\$ 20,000-\$ 29,999$ & 326 & 116643 & $0.581^{* *}$ & 1.79 & $1.52,2.11$ \\
\hline$\$ 30,000-\$ 39,999$ & 177 & 87034 & $0.411^{* *}$ & 1.51 & $1.24,1.83$ \\
\hline Income unknown & 60 & 20049 & $-0.677^{* *}$ & 0.51 & $0.38,0.66$ \\
\hline \multicolumn{6}{|l|}{ Age } \\
\hline $25-44$ & 158 & 301806 & & & \\
\hline $45-64$ & 640 & 184259 & $1.961^{* *}$ & 7.11 & $5.97,8.46$ \\
\hline 65 and above & 1076 & 93501 & $3.502^{* *}$ & 33.21 & $28.09,39.26$ \\
\hline$N$ & 1874 & 579566 & & & \\
\hline
\end{tabular}

Note: ${ }^{*}$ significant at $P<0.05 ;{ }^{* *}$ significant at $P<0.01$.

diabetes. Individuals with less than high school education were over 1.7 times as likely to die as their counterparts with some college education. In general lower family income elevated diabetes mortality risk.

In the final stage of the analysis, Hispanics were broken down into various groups according to their selfidentification in the Current Population Survey and their death information in the National Death Index. Relevant results of the multivariate proportional hazards regression estimates are shown in Table 3.
As may be seen in Table 3, Mexican Americans were $50 \%$ more likely to die from diabetes mellitus than nonHispanic whites $(\mathrm{ARR}=1.50, \mathrm{CI}=1.19,1.88)$. There was no significant association between Puerto Ricans and mortality, as the relative risk, though elevated, did not reach statistical significance. Cuban origin also did not reach significance, although the coefficients were in the negative direction. The same held for other Hispanic groups, whose numbers were too few to permit meaningful analysis: they were persons with ancestry in Colombia, El Salvador, Nicaragua, and other 
TABLE 2: Multivariate hazards regression estimates of the effect of Hispanic race on mortality from diabetes: Hispanic groups combined, $1983-1994$

\begin{tabular}{|c|c|c|c|c|c|}
\hline Covariate & Diabetes deaths & Population at risk & Hazards regression coefficient & Relative risk & 95\% confidence interval \\
\hline \multicolumn{6}{|l|}{ Race/ethnicity } \\
\hline Non-Hispanic white & 1421 & 478346 & & 1.00 & Reference \\
\hline Hispanic & 161 & 49508 & $0.246^{* *}$ & 1.28 & $1.05,1.55$ \\
\hline Non-Hispanic black & 280 & 49299 & $0.418^{* *}$ & 1.52 & $1.32,1.74$ \\
\hline Non-Hispanic other & 47 & 15992 & 0.239 & 1.27 & $0.95,1.70$ \\
\hline \multicolumn{6}{|l|}{ Nativity status } \\
\hline Born in USA & 1813 & 559517 & & 1.00 & Reference \\
\hline Born outside USA & 61 & 21518 & $-0.379^{* *}$ & 0.68 & $0.52,0.89$ \\
\hline \multicolumn{6}{|l|}{ Sex } \\
\hline Female & 1055 & 309523 & & 1.00 & Reference \\
\hline Male & 819 & 270043 & $0.240^{* *}$ & 1.27 & $1.15,1.39$ \\
\hline \multicolumn{6}{|l|}{ Marital status } \\
\hline Married & 1045 & 412040 & & 1.00 & Reference \\
\hline Not married & 829 & 166481 & $0.280^{* *}$ & 1.32 & $1.19,1.47$ \\
\hline \multicolumn{6}{|l|}{ Central city residence } \\
\hline Lives outside city & 1274 & 424934 & & 1.00 & Reference \\
\hline Lives in city & 600 & 154632 & $0.118^{*}$ & 1.12 & $1.02,1.24$ \\
\hline \multicolumn{6}{|l|}{ Health insurance } \\
\hline Has insurance & 860 & 246072 & & 1.00 & Reference \\
\hline Lacks insurance & 1014 & 333494 & -0.052 & 0.95 & $0.86,1.04$ \\
\hline \multicolumn{6}{|l|}{ Educational attainment } \\
\hline Some college & 297 & 198839 & & 1.00 & Reference \\
\hline High school & 468 & 219513 & 0.093 & 1.09 & $0.95,1.27$ \\
\hline Less high school & 1109 & 161214 & $0.558^{* *}$ & 1.75 & $1.52,2.01$ \\
\hline \multicolumn{6}{|l|}{ Family income } \\
\hline Above $\$ 40,000$ & 255 & 185130 & & 1.00 & Reference \\
\hline Less than $\$ 10,000$ & 597 & 90095 & $0.674^{* *}$ & 1.96 & $1.65,2.33$ \\
\hline$\$ 10,000-\$ 19,999$ & 519 & 100664 & $0.616^{* *}$ & 1.85 & $1.57,2.18$ \\
\hline$\$ 20,000-\$ 29,999$ & 326 & 116643 & $0.431^{* *}$ & 1.54 & $1.30,1.82$ \\
\hline$\$ 30,000-\$ 39,999$ & 177 & 87034 & $0.319^{* *}$ & 1.38 & $1.13,1.67$ \\
\hline Income unknown & 60 & 20049 & $-0.410^{* *}$ & 0.66 & $0.50,0.87$ \\
\hline \multicolumn{6}{|l|}{ Age } \\
\hline $25-44$ & 158 & 301806 & & 1.00 & Reference \\
\hline $45-64$ & 640 & 184259 & $1.913^{* *}$ & 6.78 & $5.68,8.08$ \\
\hline 65 and above & 1076 & 93501 & $3.143^{* *}$ & 23.17 & $19.42,27.64$ \\
\hline$-2 \log L$ & & & 46060.9 & & \\
\hline LRS & & & $3360.5^{* *}$ & & \\
\hline Events & & & 1874 & & \\
\hline Population at risk & & & 579566 & & \\
\hline
\end{tabular}

Note: ${ }^{*}$ significant at $P<0.05 ;{ }^{* *}$ significant at $P<0.01$.

nations in Central and South America. It is interesting to note that when Hispanic groups were disaggregated, the hazards coefficient $(\beta=0.403)$ and the associated relative risk (ARR $=1.50$ ) for Mexicans were higher than before disaggregation $(\beta=0.246 ; \mathrm{ARR}=1.28)$. This suggests that the higher Mexican risk may have been suppressed by the lower risk experienced by other Hispanic groups.

Other results worth noting include the observation that the risk experienced by Mexican Americans appears to be on par with their non-Hispanic African American counterparts.
The hazard ratios for both groups were about equal in relative size. Men were $27 \%$ more likely to die of diabetes as women $(\mathrm{ARR}=1.17, \mathrm{CI}=1.15,1.39)$. Living in the inner city was associated with significantly higher risk of mortality from diabetes $(\mathrm{ARR}=1.13, \mathrm{CI}=1.02,1.14)$.

Persons with less than high school education were $74 \%$ more likely to experience death than those with some college education $(\mathrm{ARR}=1.74, \mathrm{CI}=1.51,2.00)$. As for income, a dose-response relationship was observed between the variable and diabetes mortality risk. For instance, individuals 
TABLE 3: Multivariate hazards regression estimates of the effect of Hispanic race on mortality from diabetes: Hispanic groups disaggregated, 1983-1994.

\begin{tabular}{|c|c|c|c|c|c|}
\hline Covariate & Diabetes deaths & Population at risk & Hazards regression coefficient & Relative risk & 95\% confidence interval \\
\hline \multicolumn{6}{|l|}{ Race/ethnicity } \\
\hline Non-Hispanic white & 1421 & 478346 & & 1.00 & Reference \\
\hline Mexican & 80 & 20265 & $0.403^{* *}$ & 1.50 & $1.19,1.88$ \\
\hline Puerto Rican & 12 & 4363 & 0.027 & 1.03 & $0.57,1.82$ \\
\hline Cuban & 10 & 2621 & -0.003 & 0.99 & $0.53,1.86$ \\
\hline Other Hispanics & 59 & 22259 & -0.069 & 0.93 & $0.71,1.21$ \\
\hline Non-Hispanic black & 280 & 49299 & $0.416^{* *}$ & 1.51 & $1.32,1.74$ \\
\hline Non-Hispanic other & 47 & 15992 & 0.235 & 1.26 & $0.94,1.69$ \\
\hline \multicolumn{6}{|l|}{ Nativity status } \\
\hline Born in USA & 1813 & 559517 & & 1.00 & Reference \\
\hline Born outside USA & 61 & 21518 & $-0.368^{* *}$ & 0.69 & $0.53,0.90$ \\
\hline \multicolumn{6}{|l|}{ Sex } \\
\hline Female & 1055 & 309523 & & 1.00 & Reference \\
\hline Male & 819 & 270043 & $0.239^{* *}$ & 1.27 & $1.15,1.39$ \\
\hline \multicolumn{6}{|l|}{ Marital status } \\
\hline Married & 1045 & 412040 & & 1.00 & Reference \\
\hline Not married & 829 & 166481 & $0.281^{* *}$ & 1.32 & $1.19,1.46$ \\
\hline \multicolumn{6}{|l|}{ Central city residence } \\
\hline Lives outside city & 1274 & 424934 & & 1.00 & Reference \\
\hline Lives in city & 600 & 154632 & $0.119^{*}$ & 1.13 & $1.02,1.24$ \\
\hline \multicolumn{6}{|l|}{ Health insurance } \\
\hline Has insurance & 860 & 246072 & & 1.00 & Reference \\
\hline Lacks insurance & 1014 & 333494 & -0.054 & 0.94 & $0.86,1.04$ \\
\hline \multicolumn{6}{|l|}{ Educational attainment } \\
\hline Some college & 297 & 198839 & & 1.00 & Reference \\
\hline High school & 468 & 219513 & 0.092 & 1.09 & $0.94,1.27$ \\
\hline Less high school & 1109 & 161214 & $0.556^{* *}$ & 1.74 & $1.51,2.00$ \\
\hline \multicolumn{6}{|l|}{ Family income } \\
\hline Above $\$ 40,000$ & 255 & 185130 & & 1.00 & Reference \\
\hline Less than $\$ 10,000$ & 597 & 90095 & $0.677^{* *}$ & 1.97 & $1.65,2.34$ \\
\hline$\$ 10,000-\$ 19,999$ & 519 & 100664 & $0.616^{* *}$ & 1.85 & $1.57,2.18$ \\
\hline$\$ 20,000-\$ 29,999$ & 326 & 116643 & $0.430^{* *}$ & 1.54 & $1.30,1.82$ \\
\hline$\$ 30,000-\$ 39,999$ & 177 & 87034 & $0.319^{* *}$ & 1.37 & $1.13,1.67$ \\
\hline Income unknown & 60 & 20049 & $-0.408^{* *}$ & 0.66 & $0.51,0.87$ \\
\hline \multicolumn{6}{|l|}{ Age } \\
\hline $25-44$ & 158 & 301806 & & 1.00 & Reference \\
\hline $45-64$ & 640 & 184259 & $1.916^{* *}$ & 6.79 & $5.69,8.10$ \\
\hline 65 and above & 1076 & 93501 & $3.144^{* *}$ & 23.21 & $19.45,27.70$ \\
\hline$-2 \log L$ & & & 46055.9 & & \\
\hline LRS & & & $3365.5^{* *}$ & & \\
\hline Events & & & 1874 & & \\
\hline Population at risk & & & 579566 & & \\
\hline
\end{tabular}

Note: ${ }^{*}$ significant at $P<0.05 ;{ }^{* *}$ significant at $P<0.01$.

with family income below $\$ 10,000$ were nearly twice as likely to die as their counterparts with income above $\$ 40,000$ (ARR $=1.97, \mathrm{CI}=1.65,2.34)$. Persons making $\$ 10,000-\$ 19,999$ experienced mortality risk that was $85 \%$ more elevated than that experienced by those making $\$ 40,000$ or above $(A R R=$ $1.85, \mathrm{CI}=1.57,2.18)$. The higher the age bracket, the higher one's risk of dying from diabetes.
The second main aim of the study was to investigate whether the ethnic disparities in diabetes mortality are due in part to socioeconomic status. Testing this proposition entails comparing a baseline model (without measures of socioeconomic status) and a saturated or alternate model that includes measures of SES. In regression based on ordinary least squares, typically such a test is done via calculating 
change in the $F$-ratio (with and without the variables of interest). In proportional hazards regression, an acceptable model comparison strategy is to consider changes in the log likelihoods using the following formula:

$$
\Delta \mathrm{LL}=\mathrm{LL}_{1}-\mathrm{LL}_{2}
$$

where $\Delta \mathrm{LL}$ is change in the log likelihood, $\mathrm{LL}_{1}$ is log likelihood of the baseline (null) model, and $\mathrm{LL}_{2}$ is $\log$ likelihood of the alternate or saturated (full) model.

For more on the above formula and its application, see Kposowa [30] and Kleinbaum [39]. The change in log likelihood is distributed as a chi-squared. Determining whether the model with added covariates (the saturated) is an improvement over the baseline is judged by looking at the difference in degrees of freedom for the two models. If the difference in the log likelihood is significant at a previously selected alpha value (e.g., 0.01), then the conclusion is that the added covariates have brought about a significant reduction in the log likelihood of the baseline model.

Relevant results of the models compared are shown in Table 4. Model 1 has mainly racial/ethnic variables with Hispanics being disaggregated. Nativity status, sex, marital status, city residence, and health insurance availability are also included. As may be seen in the table, Mexican Americans were $98 \%(\mathrm{ARR}=1.98, \mathrm{CI}=1.57,2.48)$ more likely to die of diabetes as their non-Hispanic white counterparts. To perform a global test of whether socioeconomic variables explain the difference in mortality, (2) was applied to the data. Model 1 was compared with model 2 in Table 4.

Model 2 has all covariates in the baseline model, except educational attainment and income (two proxies for socioeconomic status). Calculation of the difference in log likelihood yielded 232.11. Using $\alpha=0.01$ at 7 degrees of freedom (the difference in covariates in the two models), the calculated chi-squared (232.11) was significantly different from the critical value (18.475). These findings suggest that socioeconomic position (as measured by education and income) explains part of the racial/ethnic differences observed in mortality from diabetes. In the case of Mexican Americans, this is easily seen by looking at the relative risk in model 1, which is 1.98 . When SES was taken into account (in model 2) the relative risk dropped from 1.98 to 1.50, representing a decrease of $24 \%$.

Finally, some sensitivity tests were performed to determine the stability of the estimates. One tack involved deleting health insurance (which was not statistically significant in any equation) from the final model (Table 4). Eliminating health insurance from the equation had only negligible effects on the remaining estimates. Parameter estimates are largely identical in both sign and size. For example, the adjusted relative risk of Mexican ethnicity on diabetes went from 1.50 (with health insurance in the model) to 1.496 (with health insurance deleted from the model). Effect modification was tested to check the robustness of the finding on Mexican ethnicity. More specifically, the idea was to test whether foreign born Mexicans have lower risk of diabetes mortality than US born Mexicans. Effect modification was accomplished by interacting Mexican ethnicity (a covariate category) with the foreign born (MEXFOR). This interaction term was then added to the main equation (in Table 3 ). Results (not presented in a table) showed that although the interaction term was in the expected negative direction $(b=-0.906$, ARR $=0.40, \mathrm{CI}=0.14,1.14)$, it did not reach statistical significance by conventional criteria. There were no changes in the size and direction of the main effects.

\section{Discussion}

The purpose of this study was to investigate risk factors for diabetes, concentrating on Hispanics, and to argue that there is a need in sociological and related research to avoid lumping Hispanics into one label. Data analysis provided evidence that when Hispanics are lumped together under a broad umbrella, they are much more likely to die of diabetes than whites. A key finding from this study is that it is now inappropriate in mortality research to treat Hispanics as a homogeneous group. To continue to do so would fail to find potentially important sources of difference in disease and mortality risk among the various Hispanic origin groups. It is plausible, for example, to draw some conclusion that covers all Hispanics, but it may not be valid for subgroups of that broader label. This research has shown, for example, that the generally held view in biomedicine, epidemiology, and medical sociology that Hispanics as a group are at elevated risk for diabetes death may not be accurate. The higher morbidity and mortality risk observed appears to hold because of the much higher risk experienced by Mexican Americans. Thus, once Mexicans are treated as a separate group, there are lower risks experienced by other groups, for example, Cubans and even Puerto Ricans.

The question arises as to why Mexican American diabetes mortality risk differs so much from Cuban Americans. It is plausible that there are significant differences in risk factor sets that place Mexicans at higher risk of diabetes death than Cubans. Mexican Americans, for example, have a longer history of migration (documented and undocumented) to the United States than Cubans. Compared to Mexican Americans, Cuban Americans also tend to have higher education and higher income $[19,40,41]$. It is plausible that dietary transition may occur among Mexican Americans at a higher rate due to the higher migration propensity observed in this group [23, 42]. Thus, although Mexicans living in Mexico may have diets low in carbohydrates and fat, upon entering the United States, they may take US diets that may be of less nutritional value than that in Mexico. Adopting such lifestyle change may remove protective measures that they enjoyed prior to migration [19]. It is worth noting, though, that, in Mexico itself, diabetes (type 2) is now the leading cause of death among adults, and some analysts blame changes in lifestyle and accompanying obesity for the country's unusually high diabetes prevalence rate [43]. It is plausible that there may not be much difference between Mexican immigrants and persons of Mexican ancestry born in the US, a position supported by the lack of significance for the interaction term employed in the present study. Furthermore, persons coming as immigrants, often with lower human capital, may find themselves at the lower level of the US socioeconomic ladder 
TABLE 4: Does socioeconomic status eliminate or reduce ethnic disparities in diabetes?

\begin{tabular}{|c|c|c|c|c|c|c|}
\hline \multirow{2}{*}{ Covariate } & \multicolumn{3}{|c|}{ Model 1 (baseline) } & \multicolumn{3}{|c|}{ Model 2 (saturated) } \\
\hline & $\beta$ & RR & $95 \% \mathrm{CI}$ & $\beta$ & $\mathrm{RR}$ & $95 \% \mathrm{CI}$ \\
\hline \multicolumn{7}{|l|}{ Race/ethnicity } \\
\hline Non-Hispanic white & & 1.00 & Reference & & 1.00 & Reference \\
\hline Mexican & $0.683^{* *}$ & 1.98 & $1.57,2.48$ & $0.403^{* *}$ & 1.50 & $1.19,1.88$ \\
\hline Puerto Rican & 0.348 & 1.42 & $0.79,2.51$ & 0.027 & 1.03 & $0.57,1.82$ \\
\hline Cuban & 0.129 & 1.14 & $0.61,2.12$ & -0.003 & 0.99 & $0.53,1.86$ \\
\hline Other Hispanics & 0.075 & 1.08 & $0.83,1.39$ & -0.069 & 0.93 & $0.71,1.21$ \\
\hline Non-Hispanic black & $0.641^{* *}$ & 1.90 & $1.66,2.17$ & $0.416^{* *}$ & 1.51 & $1.32,1.74$ \\
\hline Non-Hispanic other & 0.285 & 1.33 & $0.90,1.78$ & 0.235 & 1.26 & $0.94,1.69$ \\
\hline \multicolumn{7}{|l|}{ Nativity status } \\
\hline Born in USA & & 1.00 & Reference & & 1.00 & Reference \\
\hline Born outside USA & $-0.344^{* *}$ & 0.71 & $0.54,0.92$ & $-0.368^{* *}$ & 0.69 & $0.53,0.90$ \\
\hline \multicolumn{7}{|l|}{ Sex } \\
\hline Female & & 1.00 & Reference & & 1.00 & Reference \\
\hline Male & $0.230^{* *}$ & 1.26 & $1.14,1.38$ & $0.239^{* *}$ & 1.27 & $1.15,1.39$ \\
\hline \multicolumn{7}{|l|}{ Marital status } \\
\hline Married & & 1.00 & Reference & & 1.00 & Reference \\
\hline Not married & $0.431^{* *}$ & 1.54 & $1.39,1.69$ & $0.281^{* *}$ & 1.32 & $1.19,1.46$ \\
\hline \multicolumn{7}{|l|}{ Central city residence } \\
\hline Lives outside city & & 1.00 & Reference & & 1.00 & Reference \\
\hline Lives in city & 0.081 & 1.08 & $0.98,1.20$ & $0.119^{*}$ & 1.13 & $1.02,1.24$ \\
\hline \multicolumn{7}{|l|}{ Health insurance } \\
\hline Has insurance & & 1.00 & Reference & & 1.00 & Reference \\
\hline Lacks insurance & 0.033 & 1.03 & $0.94,1.13$ & -0.054 & 0.94 & $0.86,1.04$ \\
\hline \multicolumn{7}{|l|}{ Educational attainment } \\
\hline Some college & & & & & 1.00 & Reference \\
\hline High school & & & & 0.092 & 1.09 & $0.94,1.27$ \\
\hline Less high school & & & & $0.556^{* *}$ & 1.74 & $1.51,2.00$ \\
\hline \multicolumn{7}{|l|}{ Family income } \\
\hline Above $\$ 40,000$ & & & & & 1.00 & Reference \\
\hline Less than $\$ 10,000$ & & & & $0.677^{* *}$ & 1.97 & $1.65,2.34$ \\
\hline$\$ 10,000-\$ 19,999$ & & & & $0.616^{* *}$ & 1.85 & $1.57,2.18$ \\
\hline$\$ 20,000-\$ 29,999$ & & & & $0.430^{* *}$ & 1.54 & $1.30,1.82$ \\
\hline$\$ 30,000-\$ 39,999$ & & & & $0.319^{* *}$ & 1.37 & $1.13,1.67$ \\
\hline Income unknown & & & & $-0.408^{* *}$ & 0.66 & $0.51,0.87$ \\
\hline \multicolumn{7}{|l|}{ Age } \\
\hline $25-44$ & & 1.00 & Reference & & 1.00 & Reference \\
\hline $45-64$ & $2.02^{* *}$ & 7.60 & $6.38,9.05$ & $1.916^{* *}$ & 6.79 & $5.69,8.10$ \\
\hline 65 and above & $3.51^{* *}$ & 33.56 & $28.34,39.74$ & $3.144^{* *}$ & 23.21 & $19.45,27.70$ \\
\hline$-2 \log L$ & & 46288.09 & & 46055.9 & & \\
\hline$\Delta \mathrm{LL}\left(\chi^{2}\right)$ & & & & $232.11^{* *}$ & $\mathrm{df}=7$ & \\
\hline LRS & & $3133.4^{* *}$ & & $3365.5^{* *}$ & & \\
\hline Events & & 1874 & & 1874 & & \\
\hline Population at risk & & 579566 & & 579566 & & \\
\hline
\end{tabular}

Note: $\beta$ : hazards regression coefficient; RR: relative risk/hazard ratio; CI: confidence interval; ${ }^{*}$ significant at $P<0.05 ;{ }^{* *}$ significant at $P<0.01$. $\Delta \mathrm{LL}$ : change in $\log$ likelihoods (baseline alternate).

and become vulnerable to the detrimental consequences of being at that low end. A recent study [21] of diabetes among Mexicans adds support to the above argument which that analysis of diabetes was significantly impacted by income.
More bothersome, Salinas et al. [21, page 11] found that the likelihood of diabetes mortality varied by census tract level median income. The analysts observed that wealthier counties in California may have significantly less odds of 
death from diabetes than poorer counties. Likewise, poorer counties in Texas had greater odds of death from diabetes.

Findings from the present study add credence to observations made by Umaña-Taylor and Fine [28] who called for the need to recognize the fact that Hispanics are not a homogeneous group. They found that scales measuring concepts such as self-esteem and emotional autonomy were understood differently by Mexicans, Salvadorans, Colombians, and Puerto Ricans. Results in this study are, however, at variance with those reported by Borrell and Lancet [22] who found no significant differentials in mortality among Hispanic origin groups. It is important to note, however, that the Borrell and Lancet [22] study focused on all-cause mortality, whereas the present investigation has concentrated on a cause-specific mortality: diabetes. We were also unable to confirm Borrell and Lancet's [22] conclusion that Mexican Americans have better mortality profile than non-Hispanic African Americans. It is important to stress of course that the present analysis relies on one cause of death; both Mexicans and African Americans did not differ significantly from nonHispanic whites in diabetes mortality. This does not rule out the possibility that the two groups may have different health profiles if other causes of death are considered.

Low educational attainment was strongly associated with risk for diabetes mortality. A possible reason for this finding is that those with low educational attainment may be less educated with regard to diabetes risks, and they may thus be vulnerable to dying from the disease. A clear policy directive from this is that to reduce the momentum of the spread of diabetes, education may be a useful tool, especially in minority populations and neighborhoods.

Family income was easily the strongest and most consistent risk factor for dying from diabetes, a finding that supports in part the fundamental cause theory of disease and death proposed by Link and Phelan [44] and Phelan et al. [45]. Those with high income protect themselves from incurring certain diseases because they have critical resources at their disposal that can be deployed when needed. Persons or families with high income are, for example, able to live in upscale neighborhoods with easier access to multiple grocery stores and even fine restaurants. The poor and those with lower income are less free to live where they might want due to financial constraints. They may be relegated to living in communities without grocery stores, but with a proliferation of fast food restaurants-peddlers of foods with high concentrations of calories, saturated fat, and sugar, a situation that elevates the risk of obesity, which has been reported to be associated with diabetes $[46,47]$. A 2009 study of California students observed that overweight and obesity were higher among students whose school was located within one half of a mile near a fast-food restaurant, a finding that persisted even after controlling for student demographic variables and school characteristics [48].

Exercise opportunities may also be limited in poor neighborhoods due to the prohibitive costs of joining clubs that are typically absent in low income neighborhoods. Walking reasonable distances constitutes an important source of exercise that may help reduce obesity that has been linked to diabetes $[49,50]$, but even this could come with perils when the sun goes down due to fear of crime and erosion of social trust. On the basis of findings for family income and education, it appears that social disadvantage plays a key role in diabetes mortality differentials observed in the United States. We thus agree with "the twin epidemics of poverty and diabetes" in Latino neighborhoods argument made by Chaufan et al. [51, page 1032]. Many Latinos suffer from poverty; poverty, obesity, lack of physical exercise, and poor diets have been observed to be diabetes risk factors in many studies [21, 23, 52].

The study has limitations. The first is that although the data utilized constitute a prospective study of mortality, items in the Current Population Surveys were not structured to take advantage of the time-varying nature of some of the variables. Variables such as education, income, marital status, and even health insurance potentially vary with time. The NLMS collected information on individuals only at baseline (day of the interview). What happened to cohort member characteristics from the time of the survey until death or censoring is, therefore, unknown. The second limitation is that due to the restrictive nature of the data, we were unable to link individual information to city, neighborhood, or even county characteristics. Yet, as has become increasingly evident in social and epidemiologic research, most individual event outcomes are nested in larger social units. Individual outcomes, including mortality, are affected not only by personal characteristics but also by environmental and structural factors. Thus, a person living in a low income neighborhood wracked by poverty, lacking access to grocery stores, facing high levels of environmental pollution, may experience higher odds of early death from diabetes not just because of his or her individual socioeconomic position but also due to the socioeconomic condition of the neighborhood. Another limitation is that the measure of foreign born is based on country of birth. For those born outside the USA, there is no way to know the individual's immigration status and duration of residence in the country. These factors could potentially influence diabetes deaths especially with regard to their association with income and education.

Despite the above limitations, the present study has added to our understanding of the association of race/ethnicity and diabetes mortality. More importantly, it has underscored the need for future research in the social, behavioral, and biomedical sciences to refrain from treating Hispanics as a homogeneous group but to disaggregate that broader Hispanic label to the extent permitted by data.

\section{References}

[1] R. Kahn, "Report of the expert committee on the diagnosis and classification of diabetes mellitus," Diabetes Care, vol. 20, no. 7, pp. 1183-1197, 1997.

[2] Expert Committee on the Diagnosis and Classification of Diabetes Mellitus, "Report of the expert committee on the diagnosis and classification of diabetes mellitus," Diabetes Care, vol. 26, pp. 3160-3167, 2003.

[3] D. McNaughton, “Diabesity' down under: overweight and obesity as cultural signifiers for type 2 diabetes mellitus," Critical Public Health, vol. 23, no. 3, pp. 274-288, 2013. 
[4] American Diabetes Association, "Diagnosis and classification of diabetes mellitus," Diabetes Care, vol. 32, supplement 1, pp. 562-567, 2009.

[5] Centers for Disease Control and Prevention, National Diabetes Fact Sheet, General Information and National Estimates on Diabetes in the United States, Department of Health and Human Services, Atlanta, Ga, USA, 2007.

[6] National Center for Health Statistics, Health, United States, 2010: With Special Feature on Death and Dying, Hyattsville, Md, USA, 2011.

[7] R. N. Anderson, “Deaths: leading causes for 1999," National Vital Statistics Reports, vol. 49, no. 11, pp. 1-87, 2001.

[8] C. C. Cowie, K. F. Rust, E. S. Ford et al., "Full accounting of diabetes and pre-diabetes in the U.S. population in 1988-1994 and 2005-2006," Diabetes Care, vol. 32, no. 2, pp. 287-294, 2009.

[9] J. Banks, M. Marmot, Z. Oldfield, and J. P. Smith, "Disease and disadvantage in the United States and in England," Journal of the American Medical Association, vol. 295, no. 17, pp. 2037-2045, 2006.

[10] I. S. Ockene, T. L. Tellez, M. C. Rosal et al., "Outcomes of a latino community-based intervention for the prevention of diabetes: the lawrence latino diabetes prevention project," American Journal of Public Health, vol. 102, no. 2, pp. 336-342, 2012.

[11] A. Getaneh, J. C. Escand?n, and C. R. Lopez-Jimenez, "Diabetes control among hispanics in the action to control cardiovascular risk in diabetes trial," Journal of General Internal Medicine, vol. 7, no. 11, pp. 1499-1505, 2012.

[12] E. Hatcher and R. Whittemore, "Hispanic adults' beliefs about type 2 diabetes: clinical implications," Journal of the American Academy of Nurse Practitioners, vol. 19, no. 10, pp. 536-545, 2007.

[13] C. Sacerdote, F. Ricceri, O. Rolandsson et al. et al., "Lower educational level is a predictor of incident type 2 diabetes in European countries: the EPIC-Interact Study," International Journal of Epidemiology, vol. 41, pp. 1162-1173, 2012.

[14] National Center for Health Statistics, Health United States, NCHS, Hyattsville, Md, USA, 2012b.

[15] Centers for Disease Control and Prevention, Prevalence of Diabetes Among Hispanics in Six U.S. Geographic Locations, Fact Sheet, 2013, http://www.cdc.gov/diabetes/index.htm.

[16] L. P. Pabon-Nau, A. Cohen, J. B. Meigs, and R. W. Grant, "Hypertension and diabetes prevalence among U.S. Hispanics by country of origin: the national health interview survey 2000 2005," Journal of General Internal Medicine, vol. 25, no. 8, pp. 847-852, 2010.

[17] K. S. Markides and J. Coreil, "The health of Hispanics in the southwestern United States: an epidemiologic paradox," Public Health Reports, vol. 101, no. 3, pp. 253-265, 1986.

[18] P. D. Sorlie, E. Backlund, N. J. Johnson, and E. Rogot, "Mortality by Hispanic status in the United States," Journal of the American Medical Association, vol. 270, no. 20, pp. 2464-2468, 1993.

[19] A. J. Kposowa and D. Bideshi, "Reassessing the sources of racial and ethnic disparities in U. S. adult mortality," Western Journal of Black Studies, vol. 30, no. 1, pp. 1-14, 2006.

[20] A. J. Kposowa, "Is there a racial/ethnic hierarchy in health status and care," Western Journal of Black Studies, vol. 31, no. 1, pp. 1732, 2007.

[21] J. J. Salinas, S. Dejun, and S. A. Snih, "Border health in the shadow of the Hispanic paradox: issues in the conceptualization of health disparities in older Americans living in the Southwest," Journal of Cross Cultural Gerontology, vol. 28, no. 3, pp. 251-266, 2013.
[22] L. N. Borrell and E. A. Lancet, "Race/ethnicity and all-cause mortality in US adults: revisiting the Hispanic paradox," American Journal of Public Health, vol. 102, no. 5, pp. 836-842, 2012.

[23] R. H. Steckel, "The hidden cost of moving up: type 2 diabetes and the escape from persistent poverty in the American South," American Journal of Human Biology, vol. 25, no. 4, pp. 508-515, 2013.

[24] D. W. Smith and B. S. Bradshaw, "Variation in life expectancy during the twentieth century in the United States," Demography, vol. 43, no. 4, pp. 647-657, 2006.

[25] Office of Minority Health, Diabetes and Hispanic Americans, 2013, https://minorityhealth.hhs.gov/templates/content .aspx? ID $=3324$.

[26] A. J. Kposowa, "Marital status and HIV/AIDS mortality: evidence from the US National Longitudinal Mortality Study," International Journal of Infectious Diseases, vol. 17, no. 10, pp. e868-e874, 2013.

[27] US Census Bureau, U.S. Census Bureau, 2007-2011 American Community Survey, Washington, DC, USA, 2013.

[28] A. J. Umaña-Taylor and M. A. Fine, "Methodological implications of grouping Latino adolescents into one collective ethnic group," Hispanic Journal of Behavioral Sciences, vol. 23, no. 4, pp. 347-362, 2001.

[29] T. G. Pickering, "Hypertension in Hispanics," Journal of Clinical Hypertension, vol. 6, no. 5, pp. 279-282, 2004.

[30] A. J. Kposowa, "Marital status and suicide in the National Longitudinal Mortality Study," Journal of Epidemiology and Community Health, vol. 54, no. 4, pp. 254-261, 2000.

[31] US Department of Commerce, National Longitudinal Mortality Study Release 3 Documentation, Economics and Statistics Administration, US Census Bureau, Washington, DC, USA, 2008.

[32] US Department of Commerce, The Current Population Surveys, www.census.gov/cps, 2012.

[33] A. J. Kposowa, "Unemployment and suicide: a cohort analysis of social factors predicting suicide in the US National Longitudinal Mortality Study," Psychological Medicine, vol. 31, no. 1, pp. 127-138, 2001.

[34] Practice Management Information, ICD. 9.CM International Classification of Diseases 9th Revision Clinical Modification, Practice Management Information, Los Angeles, Calif, USA, 5th edition, 1998.

[35] P. Demakakos, M. Marmot, and A. Steptoe, "Socioeconomic position and the incidence of type 2 diabetes," European Journal of Epidemiology, vol. 27, no. 5, pp. 367-378, 2012.

[36] M. S. Vallen, S. Narayan, and L. Wedeking, "An innovative approach to diabetes education for a Hispanic population utilizing community health workers," Journal of Cultural Diversity, vol. 19, no. 1, pp. 10-17, 2012.

[37] D. R. Cox, "Regression models and life tables (with discussion)," Journal of the Royal Statistical Society, vol. 34, pp. 187-220, 1972.

[38] S. A. S. Institute, SAS Stats: The PHREG Procedure Version 9. 3, SAS Institute, Cary, NC, USA, 2012.

[39] D. G. Kleinbaum, Survival Analysis, Springer, New York, NY, USA, 1996.

[40] K. S. Markides and K. Eschbach, "Aging, migration, and mortality: current status of research on the hispanic paradox," Journals of Gerontology B, vol. 60, pp. 68-75, 2005.

[41] K. E. Cortes, "Are refugees different from economic immigrants? Some empirical evidence on the heterogeneity of immigrant groups in the United States," Review of Economics and Statistics, vol. 86, no. 2, pp. 465-480, 2004. 
[42] A. J. Kposowa, The Impact of Immigration on the United States Economy, University Press of America, Lanham, Maryland, 1998.

[43] S. G. Sosa-Rubí, O. Galárraga, and R. López-Ridaura, "Diabetes treatment and control: the effect of public health insurance for the poor in Mexico," Bulletin of the World Health Organization, vol. 87, no. 7, pp. 485-564, 2009.

[44] B. G. Link and J. Phelan, "Social conditions as fundamental causes of disease," Journal of Health and Social Behavior, vol. 35, pp. 80-94, 1995.

[45] J. C. Phelan, B. G. Link, A. Diez-Roux, I. Kawachi, and B. Levin, "Fundamental causes of social inequalities in mortality: a test of the theory," Journal of Health and Social Behavior, vol. 46, no. 1, pp. 265-285, 2005.

[46] B. N. Conway, M. E. May, and W. J. Blot, "Mortality among lowincome African Americans and whites with diabetes," Diabetes Care, vol. 35, no. 11, pp. 2293-2299, 2012.

[47] R. T. Demmer, A. M. Zuk, M. Rosenbaum, and M. Desvarieux, "Prevalence of diagnosed and undiagnosed type 2 diabetes mellitus among US adolescents: results from the continuous NHANES," American Journal of Epidemiology Advance, vol. 178, no. 7, pp. 1106-1113, 2013.

[48] B. Davis and C. Carpenter, "Proximity of fast-food restaurants to schools and adolescent obesity," American Journal of Public Health, vol. 99, no. 3, pp. 505-510, 2009.

[49] C. Koebnick, N. Smith, K. Huang, M. P. Martinez, H. A. Clancy, and L. H. Kushi, "The prevalence of obesity and obesity-related health conditions in a large, multiethnic cohort of young adults in California," Annals of Epidemiology, vol. 22, no. 9, pp. 609616, 2012.

[50] P. Stoddard, M. A. Handley, A. Vargas Bustamante, and D. Schillinger, "The influence of indigenous status and community indigenous composition on obesity and diabetes among Mexican adults," Social Science and Medicine, vol. 73, no. 11, pp. 16351643, 2011.

[51] C. Chaufan, M. Davis, and S. Constantino, "The twin epidemics of poverty and diabetes: understanding diabetes disparities in a low-income Latino and immigrant neighborhood," Journal of Community Health, vol. 36, no. 6, pp. 1032-1043, 2011.

[52] A. M. Kanaya, J. Santoyo-Olsson, S. Gregorich, M. Grossman, and T. Moore, "The live well, be well study: a communitybased, translational lifestyle program to lower diabetes risk factors in ethnic minority and lower-socioeconomic status adults American," Journal of Public Health, vol. 102, no. 8, pp. 1551-1558, 2012. 

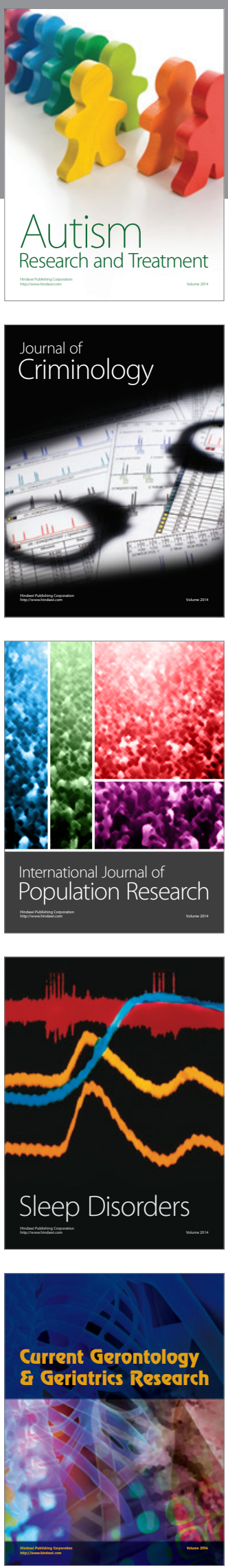
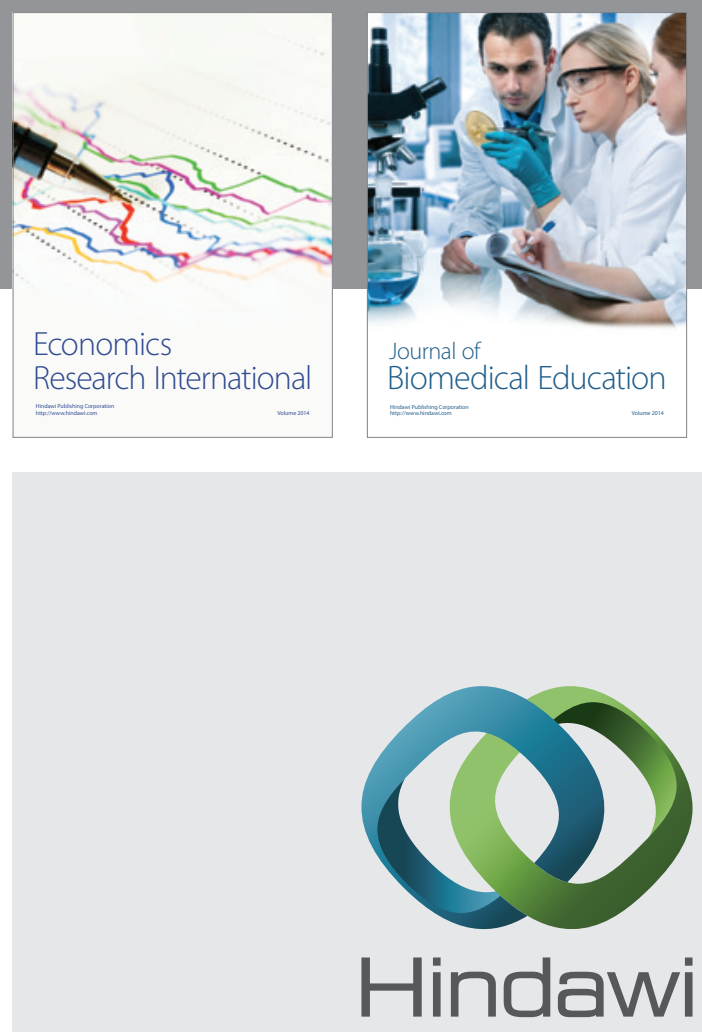

Submit your manuscripts at

http://www.hindawi.com
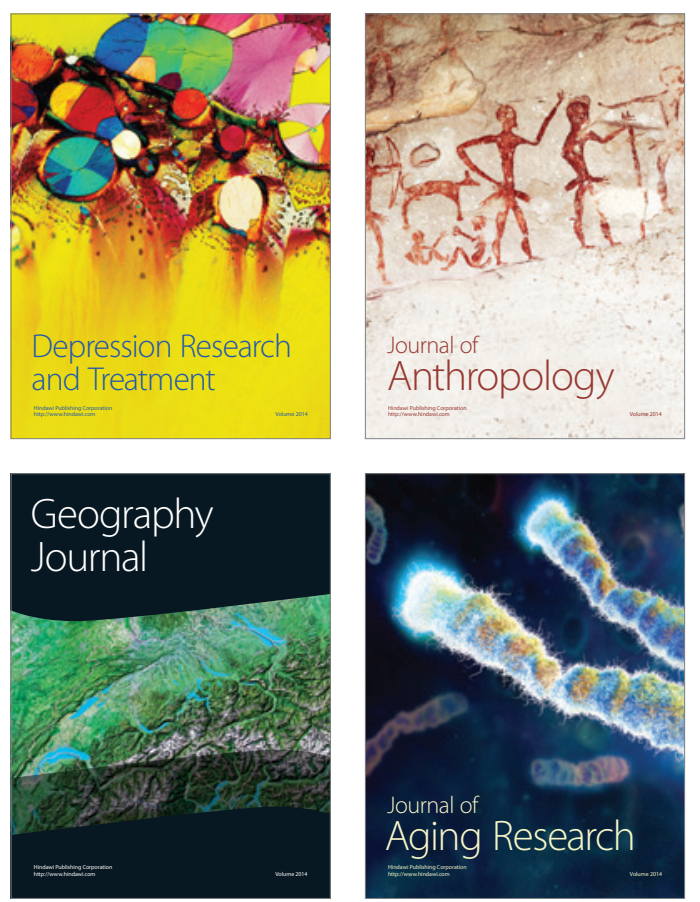
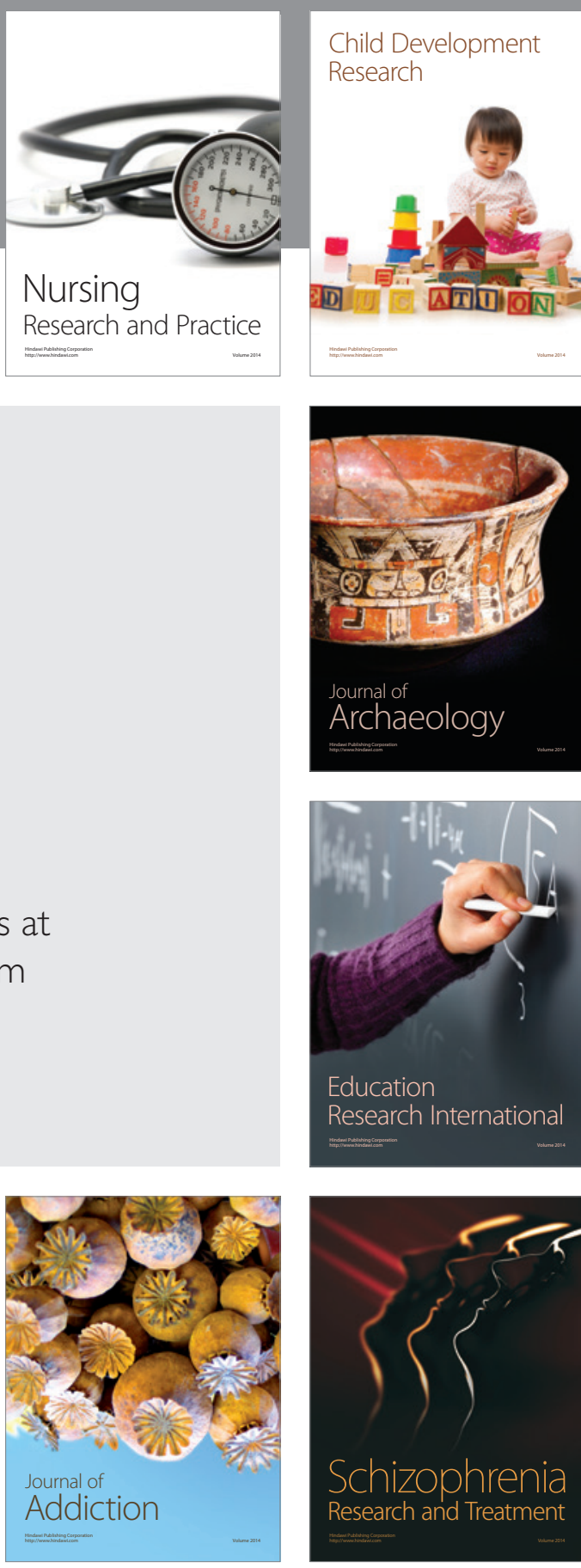

(D)
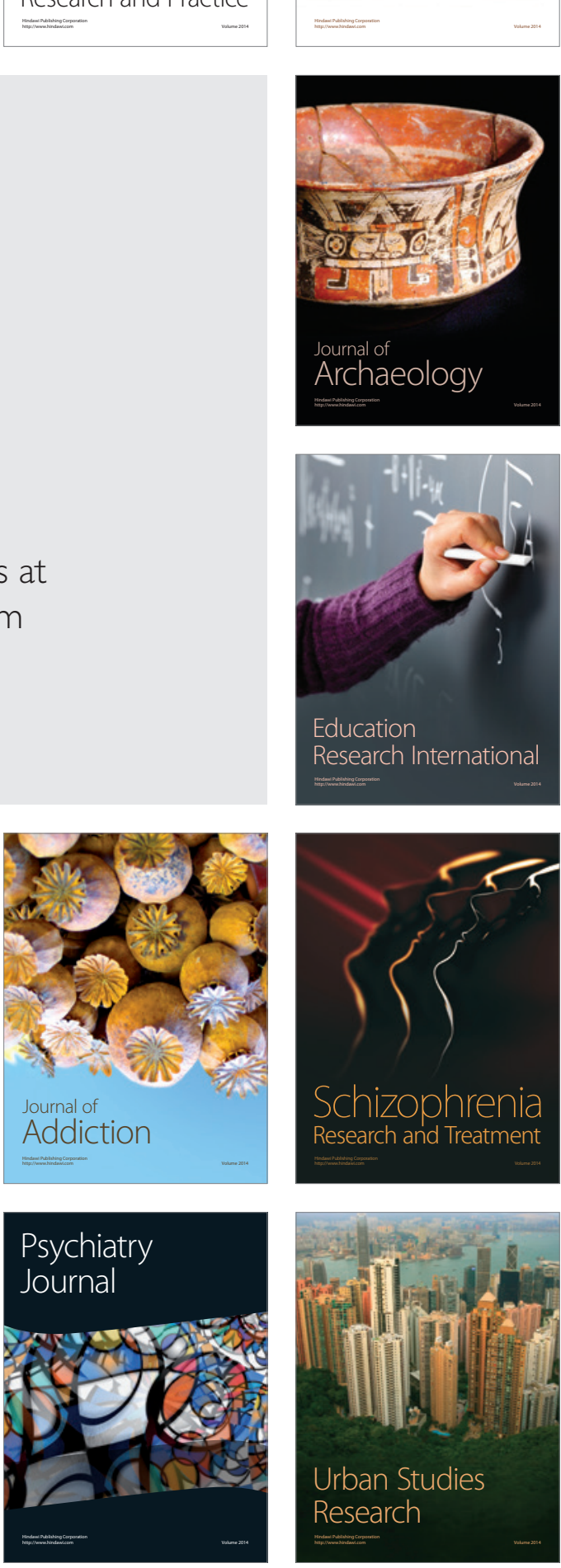